\title{
Lazer, modernidade, capitalismo: um olhar a partir da obra de Edward Palmer Thompson
}

\author{
Leisure, modernity, capitalism: an analysis from the \\ perspective of Edward Palmer Thompson's work
}

Victor Andrade de Melo

\section{Introdução}

No âmbito da pesquisa histórica, como mostra Peter Burke (1995), a possibilidade de considerar os momentos de diversão como objeto de estudo começa a se delinear melhor nos anos $1960,{ }^{1}$ configurando-se mais claramente nos anos 1970, no âmbito das propostas da Nova História Cultural e de seu intuito de considerar as práticas culturais como assuntos de primeira grandeza.

Economistas, como Thorstein Veblen, ${ }^{2}$ filósofos, como Bertrand Russell, ${ }^{3}$ ativistas e militantes, como Paul Lafargue ${ }^{4}$ e sociólogos, como Georges Simmel, ${ }^{5}$ já tinham dedicado atenção à temática do lazer. Entre os historiadores, o as-

Victor Andrade de Melo é professor do Programa de Pós-Graduação em História Comparada/IFCS, da Universidade Federal do Rio de Janeiro, e coordenador do Laboratório de História do Esporte e do Lazer (www.sport.ifcs.ufrj.br). (victor.a.melo@uol.com.br).

Artigo recebido em 11 de outubro de 2009 e aprovado para publicação em 8 de abril de 2010.

Est. Hist. Rio de Faneiro, vol. 23, no 45, p. 5-26, janeiro-junho de 2010. 
sunto adquire relevância no estudo clássico de E. P. Thompson, $A$ formação da classe operária, lançado em 1963. O próprio autor, em outra ocasião, chama a atenção: "Se retornarmos ao tema da disciplina do trabalho, ou das mudanças nos padrões familiares de conduta e lazer e aos valores comunitários durante a industrialização, o campo para o estudo comparativo parece infindável” (2001a: 194).

O processo de consolidação do modo de produção fabril configurou, paulatinamente, uma clara distinção entre a jornada de trabalho e um tempo livre. Que relação pode ser estabelecida entre essa nova dinâmica dos tempos sociais e as tensões relacionadas à constituição de um novo conjunto de comportamentos, considerados adequados para a consolidação do modelo de sociedade em construção? Essa parece ser uma questão relevante se quisermos compreender de forma mais apropriada e aprofundada, desde uma perspectiva histórica, a importância do que hoje chamamos de lazer. Abordar esse tema permite-nos, do mesmo modo, lançar mais um olhar para o processo de construção do ideário e imaginário da modernidade, para a própria consolidação da sociedade capitalista.

O presente artigo tem por objetivo discutir o tratamento dessa questão na obra de Edward Palmer Thompson. Um dos mais importantes historiadores de nosso tempo, Thompson foi um dos primeiros a abrir, dentro e a partir do marxismo, caminhos para a percepção da cultura como dimensão fundamental de luta (Hunt, 1992), e também um dos primeiros a se preocupar com uma história que considerasse melhor os anseios das massas que não têm voz, encarando-as como sujeitos ativos.

Ao recuperar em Marx a tese de que o povo se educa em sua própria práxis, como sujeito da história, Thompson entende que as suas experiências não podem ser compreendidas apenas como aquisição de comportamentos impostos, mas também como subjetivação, ressignificação, resistência quando um grupo de indivíduos compartilha um conjunto de posicionamentos contrários a determinado vetor de poder. Seriam encontrados, nos costumes, no cotidiano, férteis espaços de luta, e não somente nos fóruns institucionais. Assim, ele constrói,

uma outra tradição marxista, que não pode jamais deixar de ser crítica em relação a todo e qualquer poder instituído. Uma tradição que não pode viver só de Marx, que precisa escarafunchar eternamente a história real, os modos de dominação e as formas de resistência; não apenas a resistência presente no cenário político oficial, mas também aquela diária, incansável (Silva, 2001: 69).

Thompson postula outra compreensão sobre a relação entre a posição que o indivíduo ocupa na esfera da produção e o exercício de sua própria vonta- 
de. A consciência de classe seria "a maneira pela qual essas experiências (de relações produtivas) são manipuladas em termos culturais, incorporadas em tradições, sistema de valores, ideias" (1987a, v.1: 10). ${ }^{6}$

O desafio é compreender como se constrói uma prática política cotidiana que seja capaz de incorporar ou não certos padrões culturais, processo comumente simultâneo, que também se relacionam às questões econômicas e/ou de poder:

[...] uma cultura é também um conjunto de diferentes recursos, em que há sempre uma troca entre o escrito e o oral, o dominante e o subordinado, a aldeia e a metrópole; é uma arena de elementos conflitivos [...]. E na verdade o próprio termo "cultura", com sua invocação confortável de um consenso, pode distrair nossa atenção das contradições sociais e culturais, das fraturas e oposições existentes dentro do conjunto (Thompson, 1998a: 17).

O autor chama a atenção, também, sobre a necessidade de se deslindar mais profundamente esses componentes:

Não podemos esquecer que "cultura" é um termo emaranhado, que, ao reunir tantas atividades e atributos em um só feixe, pode na verdade confundir ou ocultar distinções que precisam ser feitas. Será necessário desfazer o feixe e examinar com mais cuidado os seus componentes: ritos, modos simbólicos, os atributos culturais da hegemonia, a transmissão do costume sob formas específicas das relações sociais e de trabalho (Thompson, 1998a: 22).

Se tivermos em conta essas ideias, não nos parecerá surpreendente identificar a presença recorrente dos temas diversão, lazer e tempo livre nas considerações do historiador inglês:

Precisaríamos de mais estudos sobre as atitudes sociais dos criminosos, soldados e marinheiros e sobre a vida de taberna; e deveríamos olhar as evidências, não com os olhos moralizadores (nem sempre os "pobres de Cristo" eram agradáveis), mas com olhos para os valores brechtianos - o fatalismo, a ironia em face das homilias, do establishment, a tenacidade da autopreservação. E devemos também lembrar o submundo do cantor de baladas e das feiras, que transmitiu tradições 
[...], pois dessa forma os "sem linguagem articulada" conservam certos valores - espontaneidade, capacidade para diversão e lealdade mútua (1987a, v. 1: 61).

A vida festiva tem seu valor reconhecido não só como válvula de escape, mas também como manutenção da pressão, da coesão, como estratégia de subversão: os momentos de diversão são eivados tanto por elementos de conservação quanto de contestação da ordem. Enfim, parece-me que as considerações de Thompson ${ }^{7}$ podem contribuir para ampliar nossas compreensões sobre a importância do lazer, já que ele

propõe uma outra maneira de buscar e investigar as "experiências" dos trabalhadores, não apenas em suas relações econômicas, mas nos seus modos de vestir e de morar, de comemorar, de festejar, de cantar, de transmitir suas tradições orais, de viver com elas ou de resistir às transformações também como vivência cotidiana, em seu dia a dia, e esta é uma nova maneira de ver a luta de classes em seu processo histórico (Fenelon, 1995: 86).

\section{O século XVIII}

O Reino Unido foi, com efeito, o primeiro país onde foram levantadas em grande escala as questões ligadas à organização do trabalho e dos lazeres eà urbanização sem precedentes que a Revolução Industrial produziu (Porter, 2001: 21).

Thompson foi um dos primeiros historiadores a defender, e a fazê-lo de forma mais contundente, a ideia de que se pode falar na existência de um Iluminismo inglês, tão importante quanto o francês, ainda que com muitas "peculiaridades":

O iluminismo desenvolveu-se na Grã-Bretanha não como uma enchente arremetendo contra um dique a despedaçar-se, mas como uma corrente a escorrer em margens erodidas, planícies lamacentas e córregos de um estuário cujos declives estão prontos para recebê-la (2001b: 120).

Os desdobramentos da Revolução Gloriosa colocaram a Inglaterra na vanguarda do progresso no século XVIII. Thompson sugere que, 
[a]o destruir a magia instituída da Igreja, o protestantismo triunfante tornou possíveis a multiplicação da racionalidade e a dispersão de iniciativas racionais por todo o país e em diferentes meios sociais. Mesmo antes de tomar posse da economia de mercado, a iniciativa privada e o laissez-faire qualificado já haviam assumido a direção da economia cultural (2001b: 119).

Naquele cenário, observa-se a gestação de novos estilos de sociabilidade, relacionados a uma nova conformação do espaço urbano, ao fortalecimento e à diversificação de um mercado consumidor, que também impactam as práticas de entretenimento, à valorização do acúmulo e da exibição de riquezas, da busca de instrução e conhecimento.

Roy Porter afirma que se a cidade inglesa caracterizava-se até então pelas atividades comerciais, naquele momento tornava-se "cada vez mais um lugar de consumo e de diversão, onde os ricos podiam mostrar-se no teatro, 'a águas' nas estâncias termais, no baile e nas lojas elegantes das avenidas. Tinha nascido a cidade do lazer" (2001: 23).

Soares (2007: 140) lembra que John Plumb, um dos primeiros historiadores a se preocupar com os momentos de diversão, percebe que o lazer tornou-se uma indústria entre 1750 e 1760, estabelecendo uma "relação direta entre a Revolução Industrial e o processo de expansão do consumo (aqui incluído o consumo relacionado ao lazer, à arte, à cultura e aos esportes), ambos aspectos fundamentais para a emergência de uma sociedade capitalista-industrial". Assim, o processo de transição da manufatura para uma indústria cada vez mais mecanizada e pesada não só tem relação com as mudanças econômicas, como também forja novos hábitos culturais.

No novo "teatro urbano", o uso e a exibição de certos produtos e a presença em determinados espaços funcionavam como elementos de status e distinção, marcando as diferenças sociais e estabelecendo mesmo horizontes de possibilidades para os que sonhavam com outra vida. Paulatinamente, mudava também o perfil do público, impelido a ter comportamentos mais controlados, e o modo de organização das atividades de entretenimento, crescentemente profissionalizadas e normatizadas.

De fato, a polaridade central do século XVIII estabeleceu-se entre a gentry e a plebe, desenhando um claro distanciamento entre ricos e pobres:

Enquanto as pessoas civilizadas reservavam diversos locais para seu uso próprio, tais como cortes, assembleias, óperas, bailes etc., as pessoas do vulgo, fazendo círculo em volta de uma praça real cha- 
mada Cercado dos Combates de Ursos de sua Majestade, tiveram sempre por quinhão os bailes, as feiras, as pândegas [...]. Bem longe de se verem, uns aos outros, como "irmãos", na linguagem cristã, dificilmente se consideravam da mesma espécie (Felding apud Thompson, 2001c: 218).

Na verdade, os mecanismos de coerção no tempo livre só se desenvolveriam mais claramente no século seguinte. Como lembra Thompson (1984: 32), "o preço que a aristocracia e a gentry pagaram por uma monarquia limitada e um Estado débil era, forçosamente, dar liberdade à multidão. Este é o contexto central estrutural da reciprocidade de relações entre governantes e governados".

Nesse contexto, infere o autor, houve mesmo um fortalecimento da cultura plebeia, graças, em grande parte, à debilidade das ações religiosas. ${ }^{8} \mathrm{O}$ historiador demonstra que os festivais e feiras constituíam, entre outras, as ocasiões mais esperadas pelos populares. Naquele instante, já se percebia claramente o seu descolamento do calendário religioso. $O$ processo de secularização fazia-se sentir na própria dinâmica das práticas de entretenimento:

No século XVIII, há uma ruptura com a Igreja: os feriados aumentam, atingindo até dois ou três dias por semana. As pessoas se dedicam a exercícios esportivos brutais, aos divertimentos sexuais, bebem muito - tudo isso escapa completamente ao controle do clero ou dos puritanos, sendo deixado ao único controle dos taberneiros, que vendem a cerveja (Thompson, 2001c: 213).

A gentry não só adotava uma postura de tolerância, como chegava diretamente a apoiar algumas dessas atividades. Ao contrário, "longe de resistir a essa cultura, nas décadas centrais do século (...) lhe outorgou um certo favor ou benefício" (Thompson, 1984: 31). Thompson supõe que essas atitudes também estavam ligadas à sua própria peculiaridade, afinal "não estava disposta a reformar seus vícios agradáveis e pomposos". Além disso, "a função valiosa do luxo era oferecer emprego e espetáculo aos pobres; [...] a ostentação do luxo e da 'generosidade' fazia parte do teatro dos poderosos" (Thompson, 1998b: 55). ${ }^{9}$

Essa "permissividade" tinha, entretanto, por limite o momento em que se percebia que as manifestações populares geravam alguma forma de organicidade que colocava certos projetos em risco. Por exemplo, lembra Thompson, quando narra os conflitos ao redor do cercamento de terras no século XVIII, que 
“à medida que o século XIX se aproximava, os direitos de recreação se tornavam mais importantes que os direitos de pastagem" (1998c: 105). Segundo o autor, "devemos a esses 'verdes' prematuros os pulmões urbanos que ainda temos atualmente”, embora, reconhece, esses espaços tenham se transformado em parques públicos altamente regulados.

Estavam semeadas as condições para que se gestasse uma solidariedade popular que teria grandes impactos na constituição definitiva de uma economia mercantil e industrializada. Não surpreende que os movimentos de contestação observáveis na Inglaterra dos anos iniciais do século XIX tenham sido de origem plebeia e não burguesa, como na França, bem como tenha sido britânica a primeira classe operária constituída.

O século XVIII inglês foi marcado pela convivência, não necessariamente tranquila, entre os primeiros momentos de uma economia renovada, sustentada na ideia de mercado e um modus vivendi ainda tradicional. $\mathrm{Na}$ transição para o século XIX, o poderio econômico da Inglaterra já era inegável e estabelecera parâmetros que seriam adotados de forma generalizada, i. e., o desenvolvimento industrial, que seria sentido mais profundamente em outros países a partir dos anos 1840.

A princípio, o modelo de produção foi "doméstico": antigos artesãos ou camponeses no tempo da não colheita trabalhando em suas próprias residências, com seus próprios recursos, manipulando a matéria-prima que compravam de mercadores, estes também responsáveis por distribuir o produto final. Logo, entretanto, o tear manual foi substituído pelo tear a vapor. A manufatura transformou-se na fábrica, a fábrica na indústria.

Thompson lembra, inclusive, que o uso do termo lazer é inadequado para alguns momentos do século XVIII, já que "persistiam a pequena lavoura e a economia doméstica, bem como em grandes áreas da indústria manufatureira, a organização do trabalho era tão variada e irregular que é ilusório traçar uma distinção nítida entre trabalho e lazer" (1998b: 52).

Conforme o novo modelo de produção foi se aperfeiçoando e se consolidando, observa-se uma maior distinção dos tempos sociais. Progressivamente, o ritmo da fábrica passou a marcar com força a vida cotidiana, delineando um tempo livre em horário definido, conforme a classe operária que se formaria fosse conseguindo sucesso em algumas de suas reivindicações, entre as quais a regulação da jornada diária e semanal (a semana inglesa), novidades que se espraiaram para outros países. Aos poucos, os tempos mais flexíveis (do ritual, da natureza, do artesanato) foram sendo substituídos pelo tempo da produção racionalizada, pelo tempo do relógio.

Discutamos mais as tensões observadas ao redor da nova dinâmica das práticas de diversão, já “práticas de lazer”, em um novo tempo, marcado pelo que 
Hobsbawm (2009: 263) chama de "gélida era da burguesia". Com a seguinte afirmação de Thompson, já podemos adiantar algo:

O século XVIII testemunhou uma mudança qualitativa nas relações de trabalho, mas sua natureza fica obscurecida se a consideramos apenas em termos de um aumento na escala e no volume da manufatura e do comércio. Isso ocorreu, sem dúvida. Todavia, ocorreu de tal maneira que uma proporção substancial da força de trabalho se tornou mais livre da disciplina do trabalho diário, mais livre para escolher entre empregadores e entre trabalho e lazer, ficando todo o seu modo de vida menos marcado por uma posição dependente do que tinha sido até então ou do que viria a ser nas primeiras décadas da disciplina da fábrica e do relógio (1998b: 42).

Vamos às décadas da disciplina da fábrica e do relógio.

\section{A transição dos séculos XVIII e XIX}

Ao discutir o processo de "auto-formação" da classe operária, Thompson apresenta uma série de indícios que podem contribuir para que visualizemos o tempo do não trabalho como campo de tensão no processo de construção da sociedade capitalista.

Segundo o autor, no fim do século XVIII, os reflexos da Revolução Francesa desencadearam uma grande preocupação na Inglaterra com a difusão de posturas dissidentes entre as camadas populares. Os ventos que vinham do outro lado do canal da Mancha dialogavam com formas divergentes de pensamento tipicamente inglesas, já em gestação desde o final do século XVII. Se havia conflitos entre a gentry e uma burguesia industrial que via aumentar seu poder, seriam feitos ajustes, tendo em vista o medo da classe operária que se configurava:

Nos anos 1790, ocorreu algo como uma "Revolução Inglesa", de profunda importância para moldar a consciência do operariado [...]. É verdade que o impulso revolucionário foi reprimido nos seus primórdios [...]. O pânico contra-revolucionário das classes dirigentes se expressava em todas as facetas da vida social: nas atitudes frente ao sindicalismo, à educação do povo em suas maneiras e diversões, às suas publicações e sociedades, e aos seus direitos políticos (Thompson, 1987a, v. 1: 195). 
Nesse cenário, foram entabuladas ações de controle que iam desde a melhoria da eficiência da atuação judicial/policial à criação de "organizações humanitárias", normalmente de cunho religioso, destinadas a "amenizar" as diferenças. Fundamentalmente, buscava-se aumentar o rigor de normas sociais. Tratava-se de manipular e reformular códigos culturais, no intuito de promover comportamentos considerados adequados para não pôr em risco o establishment. Thompson destaca que os divertimentos populares foram um dos alvos prioritários dessas ações:

As diversões dos pobres foram alvo de uma forte oposição religiosa e legal, e até mesmo as mais inócuas foram consideradas impróprias. A Sociedade pela Supressão do Vício estendeu sua esfera de ação para as "cervejas de 2 penies, bazares de pão de gengibre e quadros obscenos". Os banhistas nus eram perseguidos como se fossem criminosos sujeitos às carretas de condenados e à guilhotina (Thompson, $1987 \mathrm{a}$, v. 2: 293).

As autoridades passaram a se preocupar cada vez mais com "as tabernas, feiras e quaisquer grandes concentrações de gente - fonte de ociosidade, rixas, sedição ou contágio" (Thompson, 1987a: 60). As diversões populares eram encaradas como potencialmente perigosas por serem consideradas perturbadoras da ordem, porque se opunham à lógica do trabalho extenuado, porque estavam relacionadas a antigos estilos de vida que precisavam ser combatidos: "O processo de industrialização precisava impor o sofrimento e a destruição de modos de vida estimados e mais antigos, em qualquer contexto social concebível" (Thompson, 1987a, v.2: 29).

Além disso, era no tempo/espaço dos divertimentos que se congregavam os que sentiam os problemas do modelo de produção industrial. Se era o mundo do trabalho, da forma como estava sendo concebido, que incomodava, era no mundo do não trabalho que se tinha a oportunidade de refletir mais profundamente sobre as consequências das mudanças.

Nas tabernas, feiras e festas populares, os contestadores se reuniam para articular suas ações:

[...] sabemos que as seções nem sempre se encontravam aos domingos em casas particulares: muitas seções, nos bairros mais pobres, eram expulsas de taberna para taberna. E o relato de W. H. Reid sobre as reuniões do clube no final dos anos 1790 - com "canções onde o clero era tema constante de insultos, cachimbos e tabaco, as mesas forra- 
das com publicações de 1,2,3 penies"- parece tão plausível (Thompson, 1987a, v.1: 171).

Não parece surpreendente, assim, o número de vezes que a palavra "taberna" aparece no livro clássico de Thompson (1987a). Esses locais, onde os trabalhadores se encontravam para tomar uma cerveja após a jornada diária, tornaram-se focos de preparação da resistência política, da "conspiração". Um exemplo notável: o primeiro encontro da pioneira Sociedade Londrina de Correspondência ${ }^{10}$ se deu em $\mathrm{O}$ Sino, na Exeter Street. Tantos foram os grupos semelhantes surgidos nesses espaços que os donos dos estabelecimentos foram constrangidos a não aceitá-los mais, sob a pena de não ter sua licença renovada. Quanto às feiras e festas, afirma Thompson:

Não podemos ignorar sua importância na vida cultural dos pobres. [...]. O ano de um trabalhador ainda se compunha de ciclos de grande fadiga e provisões escassas, intercalados por dias de festa, em que a bebida e a carne eram mais abundantes, as crianças ganhavam laranjas e fitas, e as danças, o namoro, as visitas sociais e os esportes envolviam o povo (1987a, v. 2: 294).

Oferecendo alternativas múltiplas de diversão para todos os gostos, elas, ainda que momentaneamente, quebravam a escassez cotidiana comum, rompiam com a monotonia do trabalho, permitiam viver experiências um pouco mais ricas.

Como estratégias de controle, mais do que a ação jurídica e policial, havia ainda as iniciativas de cunho religioso, "um protestantismo beato, rígido, farisaico, sem intelectualismo, obcecado com a moralidade puritana a ponto de tornar a hipocrisia sua companheira automática" (Thompson, 1987a, v. 2: 263). $\mathrm{O}$ metodismo ampliou significativamente seus intentos de influenciar o operariado nascente, buscando imprimir uma lógica de vida ascética, na qual se destacava a utilização da noção de pecado como ferramenta.

Tratava-se de disciplinar o trabalhador, de levar a coerção para o interior de cada indivíduo. Afinal, propugnava-se, a felicidade só poderia ser encontrada no trabalho e em Cristo:

Visto que o mundo é a antessala da eternidade, assuntos profanos tais como a riqueza e a pobreza têm pouca importância: o rico poderia demonstrar que havia recebido a graça, servindo à igreja (sobre- 
tudo construindo capelas para seus próprios empregados). Os pobres podiam considerar-se afortunados por serem menos "tentados pelo desejo da carne e dos olhos e pelo orgulho da vida" (Thompson, 1987a, v. 2: 243).

Os metodistas empenharam-se muito no combate aos divertimentos populares; se a obrigação era considerada uma virtude suprema, o ócio deveria ser substituído pela prece e oração:

O metodismo incluiu entre suas proibições os jogos de cartas, as roupas coloridas, os ornamentos pessoais e o teatro. Escreveram-se opúsculos contra as danças e as canções "profanas". Consideravam-se profundamente suspeitas as artes e a literatura que não tivessem motivações devocionais. O terrível Sabbath vitoriano começou a estender sua opressão antes mesmo do nascimento da Rainha Vitória (Thompson, 1987a, v. 2: 300).

Isso, de certa forma, explica por que um marinheiro, começando a frequentar a religião, pedisse perdão por ter, na juventude, participado de

[...] corridas de cavalos, vigílias, bailes, feiras, frequentava casas de jogos, e mais, tanto ele esquecera o temor a seu criador e os conselhos de sua mãe que várias vezes se intoxicou com cerveja. Gostava de cantar canções profanas, contar piadas e fazer comentários jocosos e burlescos (Thompson, 1987a, v. 1: 60).

As escolas religiosas dominicais atuavam no sentido de constranger seus membros: "Na Escola de Wesley, em Kingwood, somente eram permitidas 'recreações' produtivas, como partir lenha, cavar e coisas semelhantes, posto que os jogos e brincadeiras eram 'indignos de uma criança cristã'” (Thompson, 1987a, v. 2: 256).

Enfim, como bem define o historiador, "as pressões em favor da disciplina e da ordem partiam das fábricas, por um lado, e das escolas dominicais, por outro, estendendo-se a todos os demais aspectos da vida: o lazer, as relações pessoais, a conversação e a conduta" (1987a, v. 2: 292). Há uma significativa diferença, se tivermos em conta as ações anteriores da gentry, que não combatia enfaticamente os divertimentos populares, uma postura que Thompson denomina de "paternalismo antiquado". 
Certamente, ao redor das preocupações com a "rebeldia" dos populares, havia também a necessidade de impor a nova rotina fabril, um processo difícil e tenso. Não foi fácil a adequação ao novo modelo de trabalho, não foram poucos os conflitos. Passou a ser mister, portanto, implementar uma nova lógica diária de tempo:

Nas regiões industriais, podia-se observá-la na expansão da disciplina fabril, condicionada pela campainha e pelo relógio, do trabalho às horas de lazer, dos dias úteis ao Sabbath, e também nas tentativas de repressão do "domingo do sapateiro", das feiras e dos feriados tradicionais (Thompson, 1987a, v.2: 294).

Para Thompson, o relógio é o artefato material símbolo dessa nova ordenação dos tempos sociais, uma das marcas visíveis da paulatina substituição de uma noção de tempo mais flexível por outra, de tempo cada vez mais controlado:

O que estamos examinando [...] não são apenas mudanças na técnica de manufatura que exigem maior sincronização de trabalho e maior exatidão nas rotinas de tempo [...], mas essas mudanças como são experenciadas na sociedade capitalista industrial nascente. Estamos preocupados simultaneamente com a percepção do tempo em seu condicionamento tecnológico e com a medição do tempo como meio de exploração da mão-de-obra (Thompson, 1998d: 289).

Nesse cenário marcado por tensões se desencadearam lutas pela redução e regulamentação da jornada de trabalho, estabelecidas a partir do que era possível em cada momento histórico:

A primeira geração de trabalhadores nas fábricas aprendeu com seus mestres a importância do tempo; a segunda geração formou os seus comitês em prol de menos tempo de trabalho [...]; a terceira geração fez greves pelas horas extras ou pelo pagamento de um percentual adicional pelas horas trabalhadas fora do expediente. Eles tinham aceito as categorias de seus empregadores e aprendido a revidar golpes dentro desses preceitos. Haviam aprendido muito bem a lição, a de que tempo é dinheiro (Thompson, 1998d: 294). 
A articulação entre o eco das reivindicações dos trabalhadores, posições de dissidentes que repercutiam tais proposições, uma nova perda de força do puritanismo e mesmo compreensões econômicas (o possível aumento de ganhos pela potencialização da força do trabalhador) foi forjando as condições para a delimitação do tempo diário de trabalho, a oficialização de feriados, o estabelecimento de dias livres nos fins de semana, a conquista dos direitos trabalhistas, entre os quais as férias.

Essas reivindicações causavam preocupações não só no que se refere a uma possível queda da produção, mas também porque se temia o descontrole dos populares, caso tivessem um tempo de maior liberdade, algo que inquietava até mesmo lideranças e pensadores dissidentes. Entre estes últimos, o tempo de não trabalho também foi encarado como motivo de luta. Vejamos uma reflexão de John Thelwall, um dos principais teóricos reformadores, ${ }^{11}$ ao criticar a concentração de renda, o monopólio de terras e o acúmulo de capital:

Afirmo que cada homem e cada mulher, e cada criança deve obter algo mais na distribuição geral dos frutos do trabalho, além de alimento, farrapos e uma miserável rede com uma manta pobre a cobri-la; e isso, sem ter de trabalhar doze ou quatorze horas por dia, dos seis aos sessenta anos. Eles têm uma reivindicação, sagrada e inviolável reivindicação [...] por um pouco de comodidade e divertimento [...], por algum tempo livre razoável para essas discussões, e por alguns meios ou informações que possam levá-los à compreensão dos seus direitos (apud Thompson, 1987a, v. 1: 175).

Todavia, é importante destacar que mesmo entre esses autores havia iniciativas para "moralizar" o aproveitamento do tempo disponível:

Os efeitos morais da Sociedade ${ }^{12}$ eram realmente muito grandes. Induzia os homens a lerem livros, ao invés de gastarem seu tempo nas tabernas. Ensinava-os a pensar, a se respeitarem e a desejar educar seus filhos. Elevava-os em suas próprias opiniões (Wallas apud Thompson, 1987a, v. 1: 170).

O fato é que essas organizações, que de alguma forma contribuíam para diversificar as possibilidades de lazer dos envolvidos, também não poucas vezes criticavam os antigos costumes, impondo multas por alcoolismo, desrespeito ao Sabbath, participação em jogos de apostas ou atitudes consideradas imorais. 
Na verdade, essas posturas marcaram claramente o movimento sindical no decorrer do século XIX. Não só a conquista de férias e folgas não figurava entre as prioridades, como também

[e]ste discurso sobre o mau lazer, droga para que correm os proletários, é dominante ao ponto de se encontrar tanto à esquerda como à direita do leque ideológico. A única diferença é que, num caso, o mau lazer é culpado de conduzir à desordem e à anarquia, ao passo que no outro é tratado como ópio do povo destilado pela burguesia para manter as massas numa sujeição amorfa (Thiesse, 2001: 369).

Da mesma maneira que se podia observar no comportamento de um setor das elites, percebe-se aí uma "clara reação das pessoas instruídas em relação aos divertimentos tradicionais do povo" (Thompson, 2002: 28). Esse tema foi constante na obra de Thompson e mais especialmente na de Raymond Williams. Ambos criticavam uma longa tradição inglesa que propugnava a ideia de que a cultura era um privilégio de poucos, de uma vanguarda que deveria conduzir a maioria, que supostamente não teria condições de escolher seus caminhos em meio a uma sociedade turbulenta: ${ }^{13}$

Educação e cultura, não menos que os impostos locais para os pobres, eram encaradas como esmolas que deveriam ser administradas ao povo ou dele subtraído de acordo com seus méritos. O desejo de dominar e de moldar o desenvolvimento intelectual e cultural do povo na direção de objetos predeterminados e seguros permanece extremamente forte durante a época vitoriana: e continua vivo até hoje (Thompson, 2002: 31).

Enfim:

Até mesmo os reformadores mais bem-intencionados viam seus empreendimentos como uma forma de seguro social contra os distúrbios populares. Essas reações ficaram tão entranhadas na cultura das classes superiores que podemos vê-las revividas incessantemente em cada período de agitação popular no século XIX [...]. Podem ser ainda detectadas na resposta angustiada que é dada ao "problema" do lazer da classe trabalhadora hoje em dia (Thompson, 2002: 26). 
Nesse âmbito podemos situar iniciativas como o oferecimento de um conjunto de atividades que se denominou "recreação" ou "recreação racional", ações de movimentos como o escotismo, as primeiras excursões de trabalhadores organizadas por Thomas Cook. Os "divertimentos adequados" não poucas vezes eram mesmo reconfigurações de antigas práticas populares combatidas e proibidas e, não seria equivocado dizer, higienizadas. Nesse mesmo sentido, podemos entender as ações contra certas "práticas bárbaras" (como touradas e brigas de animais) e a simultânea configuração do esporte em seu sentido moderno, que logo dialogaria com as ideias de saúde e compleição muscular.

A despeito dessas intervenções, pode-se observar que "ao invés de destruir as tradições locais [...] tenha ocorrido um crescimento da autoconsciência", [...] "na medida em que se percebiam as perdas" (Thompson, 1987a, v. 2: 299). De fato, "os entretenimentos mais rudes, desde os praticados nas festas mais sociáveis até os mais brutais, como o pugilismo e as brigas de animais" (1987a, v. 2: 295), "[...] persistiram no decorrer do século XIX com um vigor que recordava as tradições indomáveis dos aprendizes londrinos, na época dos Tudor" (1987a, v. 2: 296). O caso da Santa Segunda-Feira parece ser também luminar. Apesar dos ataques que sofreu, ela "perpetuou-se na Inglaterra até o século XIX - e, na verdade, até o século XX - por complexas razões econômicas e sociais" (Thompson, 1998d: 283).

Em outras palavras, mesmo enfrentando enormes restrições, e certamente com transformações, percebe-se a manutenção de antigos estilos de vida. Thompson lembra que

[p]raticamente até o final do século XIX, havia uma série de feiras que se realizavam por todo o país (as autoridades tentaram em vão limitar ou simplesmente proibir muitas delas), nas quais se podiam encontrar grupos de mascates, trapaceiros, ciganos autênticos ou não, cantores ambulantes e quinquilheiros (1987a, v. 2: 294).

Ainda tardaria a generalização da jornada diária capitalista: as festas e feiras eram utilizadas como forma de negativa aos intuitos de coerção; as fugas e pequenas atividades diárias de diversão, como as idas às tabernas, também. Os momentos de diversão eram, nesse sentido, e não obviamente de um ponto de vista estritamente institucional, uma forma de resistência:

Tratava-se de uma resistência consciente ao desaparecimento de um antigo modo de vida, frequentemente associada ao radicalismo político. Nesta mudança, a perda do tempo livre e a repressão ao 
desejo de se divertir tiveram tanta importância quanto a simples perda física dos direitos comunais e dos locais para recreio (Thompson, 1987a, v. 2: 300).

O historiador chama a atenção para o fato de que, no cotidiano, se estabeleciam importantes formas de luta, muitas vezes manifestas, como desordem, deficiência, indisciplina. Essas "inadequações comportamentais" eram ainda mais perceptíveis no caso dos trabalhadores irlandeses, que possuíam menor formação e comumente ocupavam os postos menos valorizados: "Eles partilhavam de um sistema de valores distintos do sistema dos artesãos ingleses; temos, inclusive, a impressão de que eles se divertiam muito, escandalizando deliberadamente os padrões de conduta ingleses" (Thompson, 1987a, v. 2: 334). Por essa postura, "representavam um elemento perturbador no seio da comunidade da classe operária em formação, um fluxo aparentemente inesgotável de reforços para as muralhas das fortalezas de Satã" (Thompson, 1987a, v. 2: 335).

Enfim, naquela transição de séculos e nas primeiras décadas do XIX, identifica-se algo aparentemente paradoxal: "uma cultura tradicional que é, ao mesmo tempo, rebelde" (Thompson, 1998a: 19). O "costume" era elemento fundamental na resistência à implementação da nova disciplina fabril, às interferências nos comportamentos, inclusive nas dinâmicas de diversão. ${ }^{14}$ Como bem resume Fortes (2006: 204):

O ímpeto disciplinador dos metodistas, porém, refletia paradoxalmente o vigor da cultura popular (as "fortalezas de satanás" dos jogos, bailes e tavernas, por exemplo), com seus espaços autônomos de sociabilidade que, embora conflitivos e plurais, possibilitavam o desenvolvimento de fortes noções de coletividade e formulação de valores diferenciados dos padrões oficiais.

Se houve algo que contribuiu centralmente para a mudança de hábitos, não foi o combate moral, não foi a ação religiosa direta, tampouco as intervenções policiais, mas sim os próprios desdobramentos da consolidação do capitalismo, que para muitos aumentou a pobreza, que eliminou a independência do artesão, que sacou das crianças o tempo de lazer doméstico e que ocasionou "para os diversos grupos de trabalhadores cujos salários reais aumentaram, a perda de segurança, e do tempo livre, ao lado da deterioração das condições ambientais urbanas" (Thompson, 1987a, v. 2: 345).

O processo de industrialização teve, aliás, impactos significativos na própria dinâmica dos espaços de diversão: 
[...] todas aquelas novas estradas, atrás das propriedades do Sr. Extorsão, do Sr. Roubo e do Sr. Unha-de-fome [...] eram antes campos abertos, onde as crianças costumavam brincar aos oito, nove, dez, onze e doze anos de idade, e passavam o tempo montando armadilhas, jogando críquete, bola, bolas de gude... e agacha-agacha (Thompson, 1987a, v. 2: 65).

\section{Conclusão}

Thompson apresenta uma fértil possibilidade de pensar os momentos de lazer a partir das lutas e tensões que se estabeleceram na sua esfera, nos instantes primordiais da configuração de uma nova classe (operária), no período inicial da Revolução Industrial. O historiador conecta trabalho e não trabalho no âmbito da formação de uma nova noção de tempo social, marcada por novos rigores:

Por meio de tudo isso - pela divisão de trabalho, supervisão do trabalho, multas, sinos e relógios, incentivos em dinheiro, pregações e ensino, supressão das feiras e dos esportes - formaram-se novos hábitos de trabalho e impôs-se uma nova disciplina do tempo (Thompson, 1998d: 297).

Para ele, o processo de consolidação do capitalismo foi claramente marcado pelos conflitos desencadeados por essa nova dinâmica. Assim,

[n]ão seria a industrialização que se teria imposto a capitalistas e trabalhadores com a força de uma lei que regeria suas relações: a busca da mais-valia relativa, como lei de acumulação de capital. Ao contrário, a industrialização seria o resultado de um processo histórico, único, pouco importando o fato de que, depois, por sua importância e características, ele se tornaria um modelo universal. Para Thompson, a grande indústria moderna é um resultado (histórico) da luta de classes (Silva, 2001: 64).

Frente às iniciativas de controle, o tempo/espaço do não trabalho, notadamente no que se refere aos divertimentos, foi uma esfera de tensão e isso gerou o aperfeiçoamento das estratégias de controle, entre as quais o próprio desenvolvimento da indústria moderna. Nesse sentido, não parece absurdo dizer que um 
dos grandes fóruns de luta para a consecução do ideário capitalista foi mesmo o âmbito do lazer, uma dimensão fundamental para garantir o "progresso".

Se a manufatura e suas novas ordenações temporais gestaram o que hoje chamamos de lazer, o novo formato da diversão no âmbito de uma sociedade marcada pela distinção dos tempos sociais, esse novo fenômeno histórico também foi um dos responsáveis pela gestação da indústria da forma como hoje a concebemos: trabalho e diversão, indústria e lazer se gestaram mutuamente.

Assim sendo, se é um equívoco pensar o lazer somente como um substrato do trabalho, abandonar a dimensão trabalho na análise da importância do lazer é igualmente equivocado. É fundamental tentar captar a complexidade em que ambos se inserem.

Mesmo no contexto de uma sociedade pós-industrial, as colocações de Thompson permanecem inspiradoras para pensarmos a importância dos momentos de lazer. Usando os termos de Weber, que também não deixou passar despercebida a relevância dos momentos do não trabalho, ${ }^{15}$ Thompson captou o "espírito do capitalismo", que, desdobrado, permanece vivo até os dias de hoje.

Em um de seus artigos encontramos algo que pode nos servir como motivação, que pode ser encarado como um desafio: "estamos agora num ponto em que os sociólogos passaram a discutir o problema do lazer. E uma parte do problema é: como o lazer se tornou um problema?" (Thompson, 1998d: 302). Certamente algumas respostas a essa questão podem ser encontradas na história, desde que os esforços de investigação sejam bem entabulados.

Vale finalizar com uma de suas proposições, ainda que possa parecer utópica. Supondo-se que, um dia, a automação possa gerar mais tempo de lazer (algo que lamentavelmente não temos observado), o autor sugere que as questões centrais passam a ser "como empregar esse tempo?" e "como a indústria de entretenimento vai disso se apropriar?". Nesse sentido, teríamos que reaprender as "artes de viver" perdidas com a Revolução Industrial, o que acabou por gerar uma enorme separação entre trabalho e vida (quando não a construção de uma representação de que o trabalho é a vida). Assim,

[s]e as pessoas vão ter de satisfazer ao mesmo tempo as exigências de uma indústria automatizada altamente sincronizada e de áreas muito ampliadas de "tempo livre", devem de algum modo combinar numa nova síntese elementos do velho e do novo, descobrindo um imaginário que não se baseie nas estações, nem no mercado, mas nas necessidades humanas. A pontualidade no horário de trabalho expressaria respeito pelos colegas. E passar o tempo à toa seria comportamento culturalmente aceito (Thompson, 1998d: 303). 
1. O autor destaca como uma evidência o fato de que o renomado periódico Past $\mathcal{E}$ Present tenha publicado uma série de conferências ligadas ao tema, entre as quais se destacou a de Keith Thomas (1964).

2. Ver A teoria da classe ociosa, escrito originalmente em 1899.

3. Ver O elogio do lazer, publicado originalmente em 1932.

4. Ver Direito à preguiça, publicado originalmente em 1880.

5. Para mais informações, ver Frisby (1989).

6. Para o autor, a classe não deve ser considerada uma estrutura, mas um fenômeno histórico que "acontece quando alguns homens, como resultado de experiências comuns (herdadas ou partilhadas), sentem e articulam a identidade de seus interesses entre si, e contra outros homens cujos interesses diferem (e geralmente se opõem) dos seus" (Thompson, 1987a, v. 1, p.10).

7. Para uma compreensão mais aprofundada sobre a obra de Thompson, além das referências citadas nesse artigo, ver Thompson (1981), Thompson (1987b), Desan (1992), Palmer (1996). Há também a revista Projeto História, n. 12, editada pelo Programa de Pós-Graduação em História da Pontifícia Universidade Católica de São Paulo, totalmente dedicada a discutir sua obra e importância.

8. De fato, desde o século XVI existia uma "tradição plebeia de anticlericalismo e irreligião" e de ceticismo materialista (Hill, 1988: 42).
9. Sobre a performance pública da gentry, ver Thompson (1998b).

10. Sobre essas sociedades, Fortes (2006: 25) observa que, "[...] embora não pudessem ser definidas como 'organizações' de trabalhadores, eram ferramentas de luta política que [...] estabeleceram as condições para o que viria a ser chamado no século XIX de socialdemocracia: a combinação das lutas em defesa da ampliação dos canais de participação política com a reorientação do sentido do desenvolvimento, da prioridade ao lucro para a prioridade às necessidades sociais”.

11. No livro Os direitos da natureza (1796), Thelwall procura ampliar as considerações do influente Direitos do homem (1791), de Tom Paine. O autor já aponta entre as reivindicações a necessidade de redução da jornada de trabalho para oito horas. Segundo Thompson (1987a, v.1: 176): "Thelwall levou o jacobinismo às margens do socialismo; levou-o também às margens do revolucionarismo".

12. Cita aqui a Sociedade Londrina de Correspondência.

13. Para maiores informações, ver Williams (1969) e Cevasco (2001).

14. Para aprofundar a visão do autor sobre a importância dos costumes, ver seus artigos sobre a venda de esposas (1998e) e o rough music (1998f).

15. Para mais informações, ver $A$ ética protestante e o espírito do capitalismo, cuja primeira edição foi lançada em 1904-1905 e a segunda revista em 1920. 


\section{Referências bibliográficas}

BURKE, Peter. The invention of leisure in early modern Europe. Past $\mathcal{E}$ Present, vol. 146, n. 1, 1995, p. 174-191.

CEVASCO, Maria Elisa. Para ler Raymond Williams. São Paulo, Paz e Terra, 2001.

DESAN, Suzanne. Massas, comunidade e ritual na obra de E. P. Thompson e Natalie Davis. In: HUNT, Lynn. A nova história cultural. São Paulo: Martins Fontes, 1992, p. 62-96.

FENELON, Déa Ribeiro. E. P. Thompson: história e política. Projeto História, n. 12, Revista da Pós-Graduação em História da PUC/SP, São Paulo: EDUC, 1995.

FORTES, Alexandre. Miríades por toda a eternidade: a atualidade de E. P. Thompson. Tempo Social, São Paulo, vol. 18, n. 1, 2006, p. 197-215.

FRISBY, David. Simmel and leisure. In: ROJEK, Chris (org.). Leisure for leisure. Nova York: Routledge, 1989.

HILL, Christopher. $O$ mundo de pontacabeça. São Paulo: Companhia das Letras, 1988.

HOBSBAWM, Eric. A era das revoluções -1789-1848. 24a edição. São Paulo: Paz e Terra, 2009.

HUNT, Lynn (org.). A nova história cultural. São Paulo: Martins Fontes, 1992.

LAFARGUE, Paul. Direito à preguiça. São Paulo: Hucitec, 1999.

PALMER, Bryan D. Edward Palmer Thompson: objeções e proposições. Rio de Janeiro: Paz e Terra, 1996.

PORTER, Roy. Os ingleses e o lazer. In: CORBIN, Alain (org.). História dos tempos livres. Lisboa: Teorema, 2001.
RUSSELL, Bertrand. O elogio do lazer. São Paulo: Companhia Editora Nacional, 1957.

SILVA, Sérgio. Thompson, Marx, os marxistas e os outros. In: NEGRO, Antonio Luigi \& SILVA, Sergio (orgs.). E. P. Thompson: as peculiaridades dos ingleses $e$ outros artigos. Campinas: Unicamp, 2001.

SOARES, Luiz Carlos. A Albion revisitada. Rio de Janeiro: 7 Letras/Faperj, 2007.

THIESSE, Anne-Marie. Organização dos lazeres dos trabalhadores e tempos roubados (1880-1930). In: CORBIN, Alain (org.). História dos tempos livres. Lisboa: Teorema, 2001.

THOMAS, Keith. Work and leisure in preindustrial society. In: Past $\mathcal{E}$ Present, vol. 29, n. 1, 1964, p. 50-62.

THOMPSON, Edward Palmer. A miséria da teoria. Rio de Janeiro: Zahar,1981.

. La sociedad inglesa del siglo XVIII: ¿Lucha de clases sin clases?. In: Tradición, reouelta y consciencia de clase: estudios sobre la crisis de la sociedad preindustrial. Barcelona: Editoral Crítica, 1984.

- A formação da classe operária. Rio de Janeiro: Paz e Terra, 1987a, 3 volumes.

Senhores e caçadores: a origem da lei negra. Rio de Janeiro: Paz e Terra, 1987b.

- Introdução: costume e cultura. In: Costumes em comum. São Paulo: Companhia das Letras, 1998a.

Patrícios e plebeus. In:

Costumes em comum. São Paulo: Companhia das Letras, 1998b.

Costume, lei e direito comum . In:

Costumes em comum. São Paulo: Companhia das Letras, 1998c. 
Tempo, disciplina de trabalho e o capitalismo industrial. In: - - Costumes em comum. São Paulo: Companhia das Letras, 1998d.

A venda de esposa. In:

Costumes em comum. São Paulo: Companhia das Letras, 1998e.

"Rough music". In: Costumes em comum. São Paulo: Companhia das Letras, 1998f.

A história vista de baixo. In: NEGRO, Antonio Luigi \& SILVA, Sergio (orgs.).E. P. Thompson: as peculiaridades dos ingleses e outros artigos. Campinas: Unicamp, 2001a.

A peculiaridade dos ingleses. In: NEGRO, Antonio Luigi \& SILVA, Sergio (orgs.).E. P. Thompson: as peculiaridades dos ingleses e outros artigos. Campinas: Unicamp, $2001 \mathrm{~b}$.

Modos de dominação e revoluções na Inglaterra. In: NEGRO, Antonio Luigi \& SILVA, Sergio (orgs.). E. P. Thompson: as peculiaridades dos ingleses e outros artigos. Campinas: Unicamp, 2001c.

——. Educação e experiência. In: - Os românticos. Rio de Janeiro: Civilização Brasileira, 2002.

VEBLEN, Thorstein. A teoria da classe ociosa. São Paulo: Nova Cultural, 1987.

WEBER, Max. A ética protestante e o espirito do capitalismo. São Paulo: Companhia das Letras, 2004.

WILLIAMS, Raymond. Cultura e sociedade (1780-1950). São Paulo: Companhia Editora Nacional, 1969.

\section{Resumo}

O processo de consolidação do modo de produção fabril paulatinamente configurou uma clara distinção entre a jornada de trabalho e um tempo livre. Que relação se pode estabelecer entre essa nova dinâmica dos tempos sociais e as tensões relacionadas à construção de um novo conjunto de comportamentos considerados adequados para a consolidação do capitalismo? Esse estudo tem por objetivo discutir o trato dessa questão na obra de Edward Palmer Thompson. Parece possível afirmar que, para ele, o controle do tempo do não-trabalho e das práticas de lazer foi compreendido como uma dimensão fundamental para garantir o "progresso".

Palavras-chave: lazer, Edward Palmer Thompson, Revolução Industrial, modernidade.

\section{Abstract}

The consolidation process of the industrial mode of production slowly configures a clear distinction between the working time and the free time. What relation can be established between this new dynamic of social times and the tensions related to the making of a new set of behaviours considered 
adequate for the consolidation of capitalism? This study aims at debating the dealing of this issue in the work of Edward Palmer Thompson. It seems possible to say that, for him, the controlling of the non-working time and the leisure practices was comprehended as an essential dimension in order to guaranteeing "progress".

Key words: leisure, Edward Palmer Thompson, Industrial Revolution, modernity.

\section{Résumé}

Le processus de consolidation de la manière de production manufacturière progressivement configure une claire distinction entre le temps du travail et un temps libre. Quel rapport se peut établir entre cette nouvelle dynamique des temps sociaux et des tensions rapportées à la construction d'un nouvel ensemble de comportements considérés appropriés pour la consolidation du capitalisme? Cette étude a comme objectif discuter le traitement de cette question à partir de l'oeuvre d'Edward Palmer Thompson. Il semble possible d'affirmer que, pour lui, le contrôle du temps du non travail a été compris comme une dimension fondamentale pour garantir la notion de "progrès". Mots-clés: loisir, Edward Palmer Thompson, Révolution Industrielle, modernité. 